\title{
Modifiye Grafit Elektrotlar Kullanılarak Bazı Tetrasiklinlerin Elektrokimyasal Davranışlarının İncelenmesi
}

\author{
Berrin GÜRLER AKYÜZ ${ }^{* 1}$, Sabriye PERÇiN ÖZKORUCUKLU2® ${ }^{2}$, Esengül KIR ${ }^{3}$ \\ ${ }^{1}$ Zonguldak Bülent Ecevit Üniversitesi, Eczacllık Fakültesi, Temel Eczacılık Bilimleri Bölümü, 67600, Zonguldak, \\ Türkiye \\ 2İstanbul Üniversitesi, Fen Fakültesi, Moleküler Biyoloji ve Genetik Bölümü, 34134, İstanbul, Türkiye \\ ${ }^{3}$ Süleyman Demirel Üniversitesi, Fen Edebiyat Fakültesi, Kimya Bölümü, 32260, Isparta, Türkiye
}

(Alınış / Received: 03.01.2021, Kabul / Accepted: 11.08.2021, Online Yayınlanma / Published Online: 25.12.2021)

\author{
Anahtar Kelimeler \\ Polipirol, \\ Tetrasiklin, \\ Klortetrasiklin, \\ Oksitetrasiklin, \\ Modifiye grafit, \\ Diferansiyel puls
}

Özet: Bu çalışmada, Tetrasiklin (TC), Klortetrasiklin (CTC) ve Oksitetrasiklin'in (OTC) elektrokimyasal davranışları \% 20; 30 ve 40 asetonitril-su karışımlarında hazırlanan Britton-Robinson (BR) tamponlarında $\mathrm{pH} 1,5 ; 2 ; 2,5 ; 3$ ve 4'te diferansiyel puls voltametri yöntemiyle incelenmiștir. TC, CTC ve OTC'nin voltametrik tayinleri moleküler baskılı (MIP) ve baskısız (NIP) polimer modifiye grafit elektrotlar kullanılarak gerçekleştirilmiştir. Her iki tür elektrot da dönüşümlü voltametri yöntemiyle hazırlanmıştır. Asetonitril-su oranı ve pH'nın modifiye grafit elektrodun performansı üzerine olan etkisi incelenmiş ve optimize edilmiştir. TC, CTC ve OTC için modifiye grafit elektrot ile en yüksek anodik sinyaller \%20 asetonitril-su karıșımında hazırlanan BR tamponu ile pH 2'de elde edilmiștir.

\section{Investigation of Electrohemical Behaviors of Some Tetracyclines Using Modified Graphite Electrodes}

\section{Keywords}

Polypyrrole,

Tetracycline,

Chlortetracycline,

Oxytetracycline,

Modified graphite,

Differential pulse

\begin{abstract}
In this study, electrochemical behavior of tetracycline (TC), chlortetracycline (CTC) and oxytetracycline (OTC) were investigated in 20; 30 and $40 \%$ acetonitrile-water mixture at the $\mathrm{pH}$ of $1.5 ; 2 ; 2.5 ; 3 ; 4$ prepared BrittonRobinson (BR) buffers, by the differential pulse voltammetric method. Voltammetric determinations of TC, CTC and OTC were carried out using molecularly imprinted (MIP) and non-imprinted polypyrrole (NIP) modified graphite electrodes. Both types of electrode were prepared by the cyclic voltammetric method. The effect of the asetonitrile-water ratio and $\mathrm{pH}$, on the performance of the modified graphite electrode (MIP) was investigated and optimized. The highest anodic signals of TC, CTC and OTC with modified graphite electrode were obtained in BR buffer solution were prepared in $20 \%$ asetonitrile-water at $\mathrm{pH} 2$.
\end{abstract}

\section{Giriş}

Mikroorganizmaların neden olduğu enfeksiyonlara karşı kullanılan (virüsler dışındaki), çeşitli mikroorganizmalardan elde edilen veya sentez yoluyla üretilen ilaçlar 'antibiyotikler' olarak adlandırılır. İlk antibiyotik olan penisilinin keşfedilmesinden sonra sülfonamidler de tedavide yerini alarak pek çok hastalığın iyileştirilmesinde kullanılmıștır [1]. Tetrasiklin grubu antibiyotiklerden ise kimyasal olarak ilk saflaştırılanı klortetrasiklindir. [2]. Kısa süre sonra diğer doğal tetrasiklinler olan oksitetrasiklin, tetrasiklin ve dimetilklortetrasiklin de elde edilerek tedavide kullanılmaya başlanmıştır. Doğal tetrasiklinlerden sonra kimyasal yapısı birbirine benzeyen yarı sentetik türevler olan metasiklin, doksisiklin ve minosiklin geliştirilmiștir [3].

Antibiyotik tedavisinde aranılan en önemli özellik ilacın seçici olmasıdır, yani mikroorganizma hücresini tahrip ederken, konakçı hücresine zarar vermemesidir. Bir antibiyotiğe duyarlı mikroorganizma türlerinin tümüne o ilacın spektrumu denir. Her antibiyotiğin etki spektrumu aynı değildir, bazıları dar, bazıları da geniş spektrumludur. Geniş spektrumlu antibiyotiklere örnek kinolonlar, sülfonamidler ve tetrasiklinler verilebilir, bunlar oldukça fazla mikroorganizmaya karşı etkilidirler ve birçok enfeksiyöz hastalı̆ı̆ı tedavisinde kullanılırlar. 
<smiles>CN(C)[C@H]1C(O)=C(C(N)=O)C(=O)[C@@]2(O)C(O)=C3C(=O)c4c(O)cccc4[C@@](C)(O)C3CC12</smiles>

(a)<smiles>CN(C)[C@H]1C(O)=C(C(N)=O)C(=O)[C@]2(O)C(O)=C3C(=O)c4c(O)ccc(Cl)c4[C@@](C)(O)C3C[C@H]12</smiles>

(b)<smiles>CN(C)[C@H]1C(O)=C(C(N)=O)C(=O)[C@]2(O)C(O)=C3C(=O)c4c(O)cccc4[C@@](C)(O)C3[C@@H](O)[C@@H]12</smiles>

(c)

Şekil 1. TC (a), CTC (b) ve OTC'nin (c) kimyasal formülleri

Antibiyotik tedavisinde önemli olan diğer bir özellik de direnç oluşmasıdır. Mikroorganizmaların tedavi sırasında bir antibiyotiğe karşı duyarlılığında azalma görülmesine direnç denir [1]. Bu konudaki en büyük endişe, modern hayvancılı uygulamalarında antibiyotiklerin, tedaviden çok hastalık önleme amaçlı kullanılmaları durumunda ortaya çıkmaktadır. Tetrasiklinler, geniş spektrumlu olma özelliklerinden dolayı veterinerlikte de yaygın olarak kullanılan antibiyotikler arasındadır. Bu nedenle de çok sayıda hayvansal gıda maddesinde kalıntılarına rastlanabilmektedir [4].

Tetrasiklin kalıntılarının belirlenebilmesi için çok sayıda kromatografik, spektrofotometrik, potansiyometrik ve amperometrik yöntemler kullanılmıştır. Tayin ve ayırmayı iyileștirecek alternatif bir yöntem ise voltametrik yöntemlerdir.

Moleküler baskılı polimer modifiye grafit elektrotlar, kurşun kalem ucu yüzeyinde pirolün elektropolimerizasyonu yoluyla elde edilmekte ve voltametrik yöntemlerde çalışma elektrodu olarak kullanılmaktadır. Moleküler baskılı polimerler, hedef moleküle ya da yapısal olarak ilgili moleküle karşı yüksek afinite ve seçicilik gösteren çapraz bağlı polimerlerden oluşmaktadır. Bu materyaller eser miktardaki analite dahi bağlanmakta, benzer fizikokimysal özellikleri gösteren diğer bileşiklerin varlığında bile yüksek seçicilik gösterebilmektedir. Hazırlanması kolay, dayanıklı, ucuz ve dış etkilere karşı fiziksel ve kimyasal kararlılı̆̆ı oldukça yüksek polimerlerdir.

Polipirol çeşitli iletken polimer tipleri arasında "moleküler tanıma sistemi" gibi çekici bir özelliğe sahiptir. Ayrıca nötral pH'da kullanılabilmekte ve çeşitli elektrot materyalleri üzerinde kararlı filmleri rahatlıkla polimerize olabilmektedir.

$\mathrm{Bu}$ çalışmada, tetrasiklinlerin elektrokimyasal davranışlarının diferansiyel-puls voltametri yöntemiyle incelenmesi için polipirol bazlı modifiye grafit elektrotlar hazırlanmıştır. Modifiye grafit elektrotlar, moleküler baskılı ve baskısız olmak üzere iki türde ve dönüşümlü voltametri yöntemiyle elde edilmiştir. TC, CTC ve OTC'nin elektrokimyasal davranışlarının belirlenmesi için diferansiyel-puls voltametrisi yöntemiyle çeşitli pH'larda ve farklı asetonitril-su ortamlarında hazırlanan BR tamponlarında çalışılmıştır.

\section{Materyal ve Metot}

\subsection{Cihazlar ve elektrotlar}

Elektrokimyasal çalışmalar yazılım programı GPES 4.9 olan Autolab/PGSTAT 302 N (Metrohm Autolab, Hollanda) cihazı ile kaydedilmiştir. Ölçümler beş boyunlu cam hücrede üç elektrotlu sistemle alınmıştır. Tüm elektrokimyasal çalışmalar $25^{\circ} \mathrm{C}$ ve azot atmosferinde gerçekleştirilmiştir.

Polipirolle modifiye edilen hedef molekül baskılı ve baskısız grafit elektrotlar çalışma elektrodu, sulu $\mathrm{Ag} / \mathrm{AgCl}(3 \mathrm{M})$ referans elektrot, Pt tel ise karşı elektrot olarak kullanılmıştır. Ortam pH'ları Seven Mettler Toledo Multi pH/iyon metre kullanılarak ayarlanmıștır.

\subsection{Kimyasallar}

Lityum perklorat (ultra $\geq \% 99,0$ ), Sigma Aldrich; pirol $(\geq \% 97)$, potasyum hidrojen fitalat $(\geq \% 99,5)$, sodyum hidroksit ( $\geq \% 97)$, asetik asit $(\geq \% 99,8)$, orto-fosforik asit (\%85), asetonitril $(\geq \% 99,9)$ ve borik asit (\%99,5$100,5)$ Merck firmasından temin edilmiștir. Kullanılan bütün kimyasal maddeler analitik saflıktadır. İletkenliği 18,2 $\mathrm{M} \Omega \mathrm{cm}$ ultra-saf deiyonize su, Millipore Milli-Q su arıtma sistemiyle elde edilmiștir.

\subsection{Kullanılan elektrokimyasal yöntemler}

\subsubsection{Dönüşümlü voltametri yöntemiyle moleküler baskılı (MIP) ve baskısız (NIP) elektrotların hazırlanması}

Çalışmada grafit elektrotların polipirol ile modifiye edilmesinde hedef molekül ile eşzamanlı polimerizasyonun sağlanması için dönüşümlü voltametri tekniği kullanılmıştır.

Moleküler baskısız polimer modifiye grafit elektrotların hazırlanmasında; 0,1 M pirol monomeri; 0,1 M lityum perklorat destek elektroliti içeren çeşitli yüzdelerdeki asetonitril-su karışımlarının çözeltileri kullanılmıștır.

Moleküler baskılı polimer modifiye grafit elektrotların hazırlanmasında; 0,1 M pirol monomeri; 0,1 M lityum perklorat destek elektroliti ve 500 ppm TC ( TC, CTC, OTC) içeren çeşitli yüzdelerdeki asetonitril-su karışımlarının çözeltileri kullanılmıştır. 
Elektropolimerizasyon işlemi grafit kalem ucu (HB, çapi $0.7 \mathrm{~mm}$, Tombo, Japan) elektrot yüzeyinin $-0,6 \mathrm{~V}$ ile $+0,8 \mathrm{~V}$ potansiyel aralı̆̆ında $100 \mathrm{mV} / \mathrm{s}$ tarama hızında dönüșümlü voltametri ile 5 döngü [5-7] alınarak polipirolle kaplanmasiyla gerçekleştirilmiştir. Potansiyel aralığın belirlenmesi çalışmalarında, potansiyel değer $-0,6$ V'dan $+1,4$ V'a kadar, 0,1 V'luk aralıklarla artırılarak denenmiş ve $+0,8$ V'dan daha yüksek değerlerde elektrot kaplamalarında bozulmalar gözlenmiștir. Bu yüzden uygun potansiyel aralığının $-0,6 \mathrm{~V}$ ile $+0,8 \mathrm{~V}$ aralığında olmasina karar verilmiştir $[6,8,9,10]$. Hazırlanan NIP ve MIP elektrotlara, 0,1 M sodyum hidroksit çözeltisinde $+0,8 \mathrm{~V}$ ile $+1,2 \mathrm{~V}$ aralığında, 50 $\mathrm{mV} / \mathrm{s}$ tarama hızında 20 döngülü $[5,6,10]$ potansiyel taraması uygulanarak aşırı yükseltgeme işlemi yapılmıştır.

Aşırı yükseltgeme işlemi polipirolün iletkenliğinin ve elektroaktivitesinin azalmasına neden olmaktadır. Uygulanan aşırı yükseltgeme ișlemi ile aynı zamanda moleküler olarak baskılanmış olan TC'lerin yapıdan uzaklaştırılması sağlanmaktadır. Bu işlem sonucunda polipirolün yapısına oksijen içeren türler katılmakta ve polipirolde hedef moleküle özgü boşluklar oluşmaktadır.

\subsubsection{Diferansiyel puls voltametri yöntemiyle tetrasiklin grubu bileşiklerin elektrokimyasal davranışlarının belirlenmesi}

TC'lerin elektrokimyasal davranışlarının belirlenmesi işlemi sırasıyla NIP ve MIP elektrotlar ile BR tamponlarında diferansiyel puls voltametrisi yöntemiyle yapılmıştır. DP voltamogramları çalışılan pH ve ortamdaki (\% asetonitril-su karışım oranı) BR tamponunda hazırlanan $25 \mathrm{mM}$ tetrasiklin (TC, CTC, OTC) çözeltilerinden $0,05-10 \mathrm{mM}$ aralığındaki derişimlerin hücreye eklenmesiyle kaydedilmiştir. TC'lerin elektrokimyasal davranışları \%20, 30 ve 40 asetonitril-su karışımlarında ve farklı pH değerlerinde $(1,5 ; 2 ; 2,5 ; 3$ ve 4) hazırlanan BR tamponları kullanılarak incelenmiştir.

\section{Bulgular}

\subsection{Asetonitril-su oranının elektrokimyasal davranış üzerine etkisi}

Tetrasiklinlerin elektrokimyasal davranışı üzerine \% asetonitril-su karışım oranının etkisini incelemek için $\% 20,30$ ve 40 asetonitril-su karışımlarında BR tamponları hazırlanmıştır. Çalıșılan üç adet tetrasiklin grubu bileşiğin maksimum yükseltgenme akımlarının gözlendiği ortam \%20 asetonitril-su karışımında hazırlanan BR tamponunda olmuştur [10].

\subsection{Elektrokimyasal davranış üzerine $\mathbf{p H}$ etkisinin incelenmesi}

Tetrasiklinlerin elektrokimyasal davranışı üzerine $\mathrm{pH}$ etkisinin incelenmesi için yukarıda bahsedilen \%20,
30 ve 40 asetonitril-su karışımlarında hazırlanan BR tamponları 1,$5 ; 2 ; 2,5 ; 3$ ve 4 olmak üzere farklı pH'lara ayarlanmıștır. pH 1,5'te yapılan çalışmalarda yüksek akım değerleri kaydedilse de, ortamın çok asidik olması ve madde yapısının bu ortamda bozulması nedeniyle sonuçların doğru ve tekrarlanabilir olmadığı saptanmıștır. Hazırlanan farklı ortamlardaki çalışma sonuçlarına göre tüm yüzdelerdeki $\mathrm{pH}$ taramalarından pH 2 en yüksek akımın elde edildiği ortam pH'ı olarak; \%20 asetonitril-su karışımı ise optimum BR tamponu ortamı olarak saptanmıştır [10].

\% Asetontril-su karışımının ve pH'nın modifiye grafit elektrotların akım cevapları üzerine etkisinin incelendiği çalışmalardan çizilen derişim-akım grafikleri aşağıdaki şekillerde verilmiş, ayrıca elde edilen sonuçlar Tablo 1. 'de gösterilmiştir.

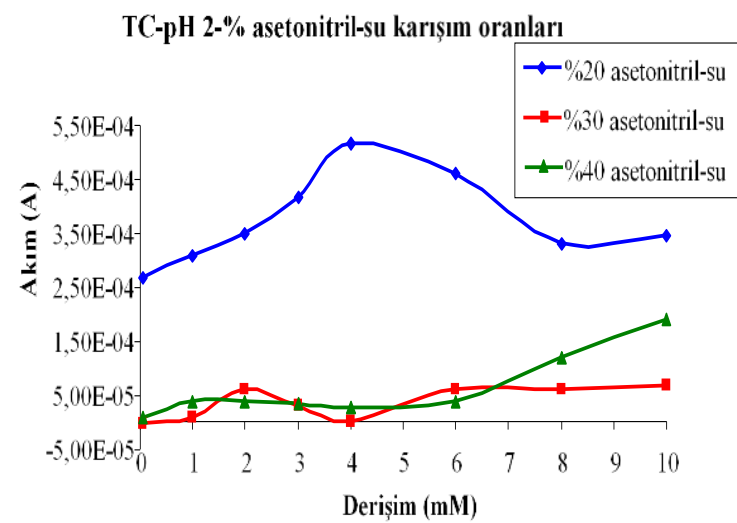

(a)

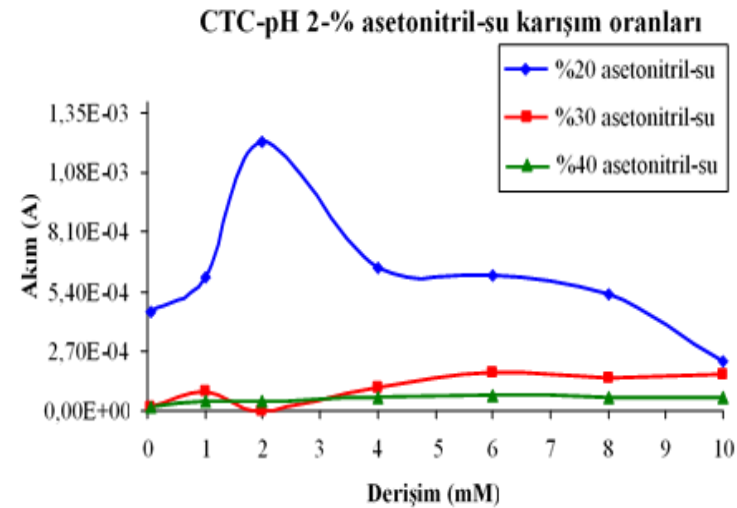

(b)

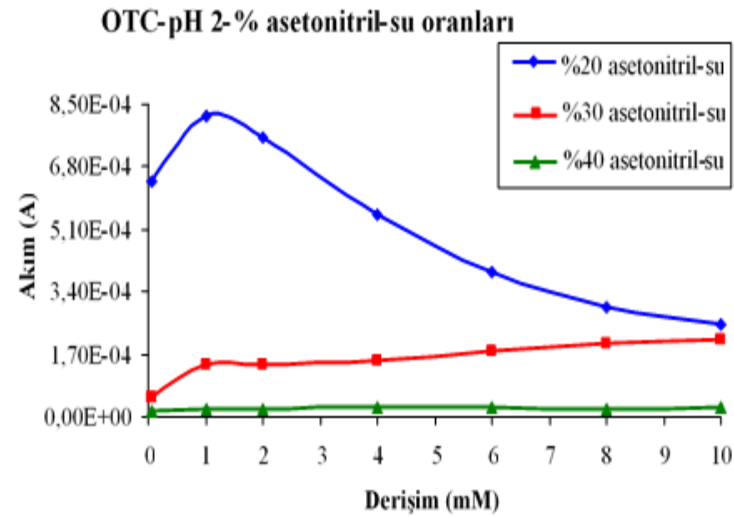

(c)

Şekil 2. TC (a), CTC (b) ve OTC'nin (c) \% asetonitril-su karışım oranlarındaki karşılaştırma grafikleri 


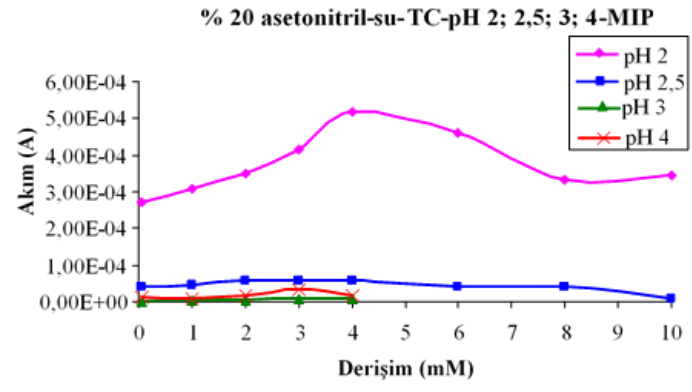

(a)

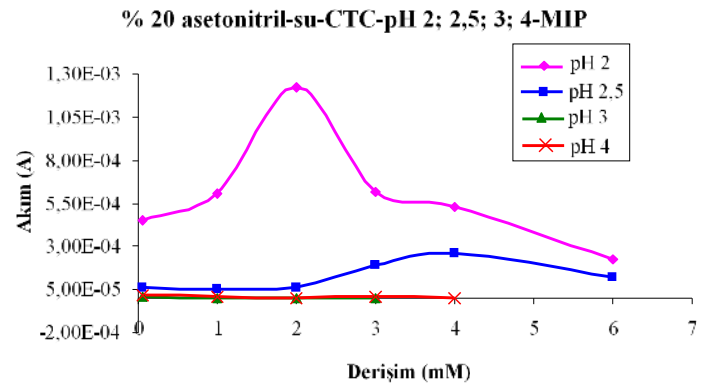

(b)

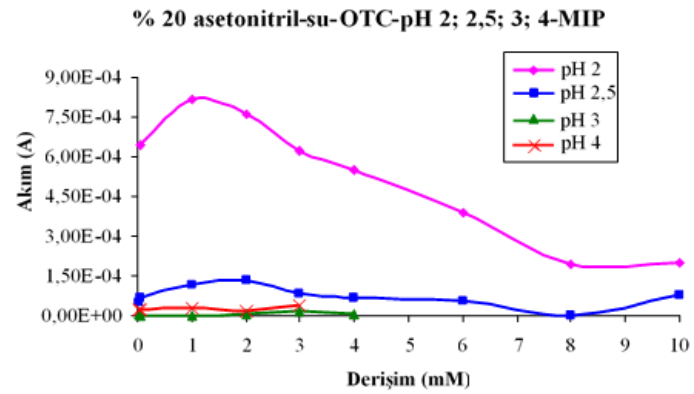

(c)

Şekil 3. TC (a), CTC (b) ve OTC (c) için \%20 asetonitril-su karışımında $\mathrm{pH}$ taramaları

Tablo 1. TC, CTC ve OTC için elde edilen optimum çalıșma ortamları

\begin{tabular}{ccc}
\hline Bileşik & $\begin{array}{c}\text { Optimum Asetonitril-su } \\
\text { oranı (\%) }\end{array}$ & Optimum pH \\
\hline TC & $20: 80$ & 2,0 \\
CTC & $20: 80$ & 2,0 \\
OTC & $20: 80$ & 2,0 \\
\hline
\end{tabular}

Yapılan uygun çalışma ortamının ve pH'nın belirlenmesi çalışmalarına göre en uygun çalışma ortamının \% 20 asetonitril-su karışımındaki pH 2 BR tampon çözeltisi olduğu belirlenmiştir.

Bulunan optimum ortamlarda her üç antibiyotik için derişim taramaları yapılmış ve derişim arttıkça ölçülen akım değerlerinin de arttığı gözlenmiştir. Artan derişime karşı elde edilen akım değerlerinin voltamogramları Şekil 4.'te verilmiştir.

Ayrıca MIP ve NIP elektrodun seçiliğinin belirlenmesi için aşırı yükseltgenen her iki tür elektrotla optimum deney şartlarında alınan ölçüm sonuçları karşılaştırılarak hangi tür elektrodun tetrasiklin grubu bileşiklere karşı daha duyarlı ve seçici davrandığı tespit edilmiş ve tetrasiklinlerin moleküler baskılandı̆̆ polipirol modifiye grafit elektrotların baskısız elektrotlara göre daha seçici ve duyarlı olduğu belirlenmiştir. MIP elektrotların daha seçici özellik göstermelerinin nedeni, aşırı yükseltgeme sonucu yapıya giren oksijen içeren türlerin sayesinde katyonik yüklerin azalması ve böylece polipirol filmlerinin ilaçlar gibi katyonik türlere karşı seçici hale gelmeleridir. MIP elektrotlarla elde edilen pik akım değerlerinin NIP elektrotlara göre daha yüksek olması MIP elektrotların katyonik formdaki TC'lere karşı daha duyarlı olduğu sonucunu doğrulamaktadır. Sonuçlar Şekil 5.'te karşılaştırmalı olarak verilmiştir.

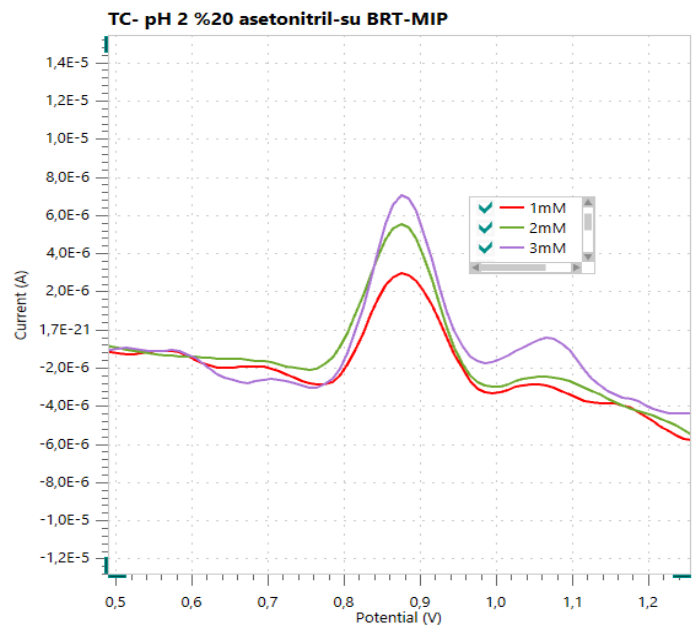

(a)

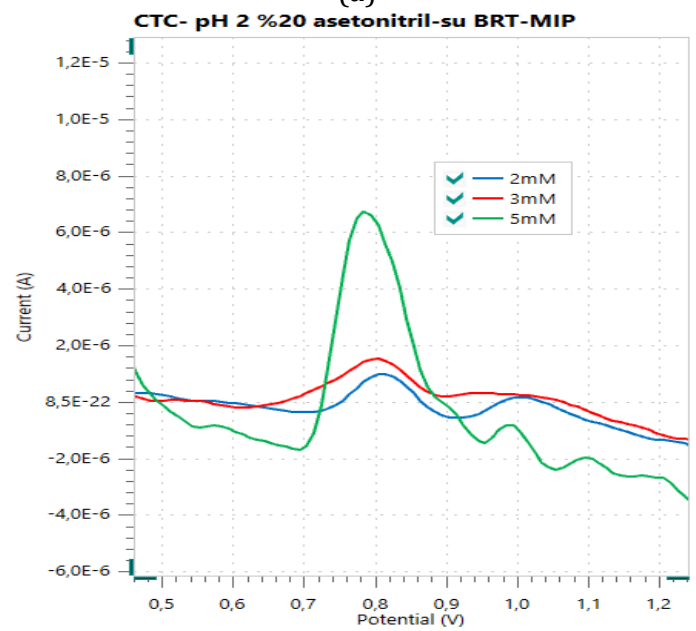

(b)

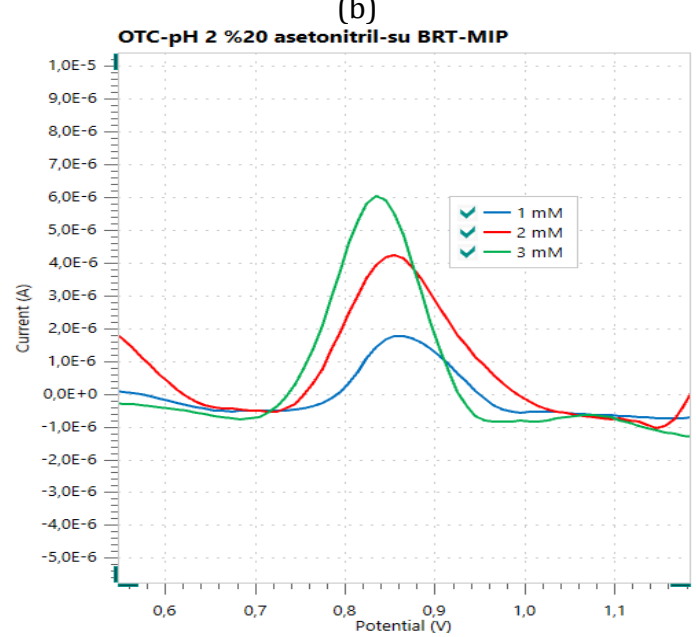

(c)

Şekil 4. TC (a), CTC (b) ve OTC (c) için MIP elektrotla farklı derişimlerde alınan diferansiyel puls voltamogramları 


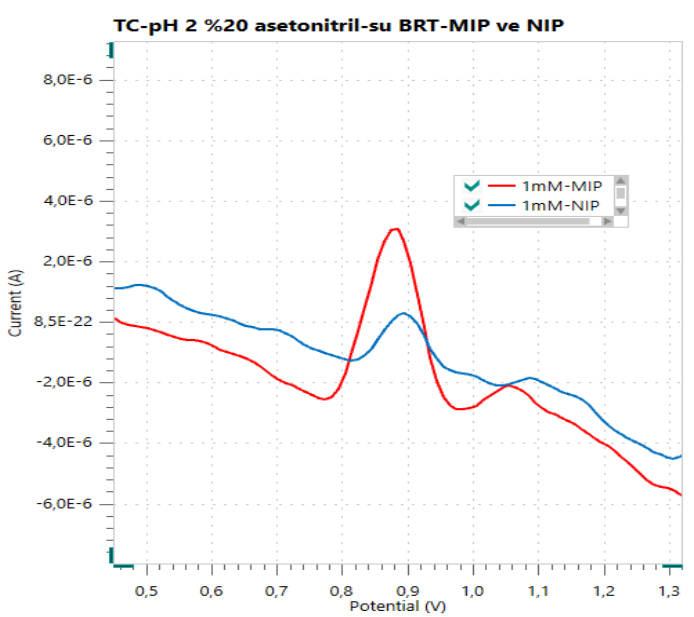

(a)

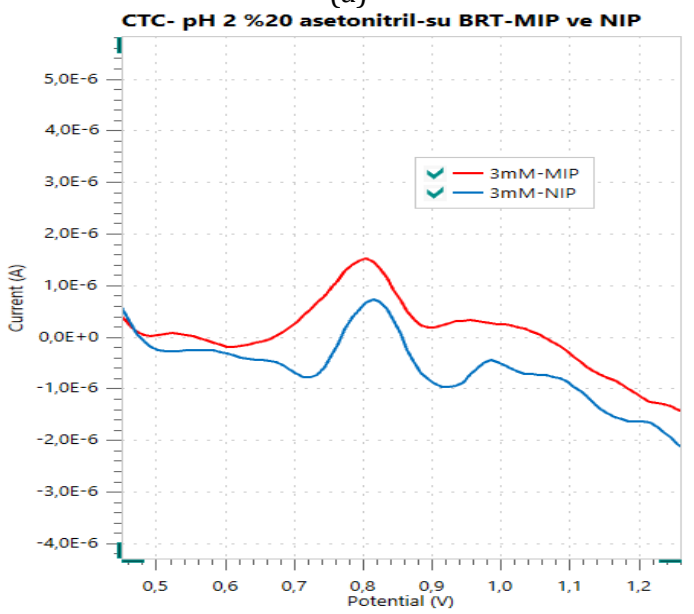

(b)

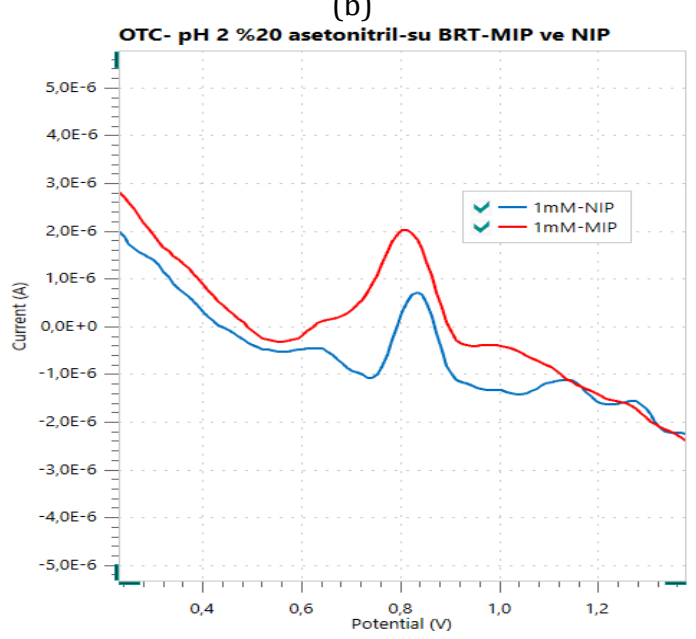

(c)

Şekil 5. TC (a), CTC (b) ve OTC (c) için MIP ve NIP elektrodun diferansiyel puls voltamogramlarının karșılaștırılması

TC, CTC ve OTC standartları ile yapılan ölçümlerden elde edilen tayin limitleri ve yüzde geri kazanımlar aşağıdaki tabloda sunulmuştur.

Tablo. 2 TC, CTC ve OTC için tayin sonuçları

\begin{tabular}{ccccc}
\hline Bileşik & $\begin{array}{c}\text { LOD } \\
\text { (mM) }\end{array}$ & $\begin{array}{c}\text { LOQ } \\
\text { (mM) }\end{array}$ & \%BSS & $\begin{array}{c}\text { Geri } \\
\text { Kazanım (\%) }\end{array}$ \\
\hline TC & 0,011 & 0,037 & 0,67 & 96,3 \\
CTC & 0,014 & 0,047 & 0,82 & 93,7 \\
OTC & 0,012 & 0,040 & 0,74 & 95 \\
\hline
\end{tabular}

\section{Tartışma ve Sonuç}

TC, CTC ve OTC'nin elektrokimyasal analizlerinin yapılabilmesi için öncelikle elektrokimyasal davranışlarının belirlenmesi gerekmektedir. TC'lerin elektrokimyasal davranışlarının incelenmesi aşamasında ilk olarak elektropolimerizasyon yöntemiyle grafit kalem uçları polipirol filmler ile kaplanmış ve TC’lerin eşzamanlı moleküler baskılandığı polipirol modifiye grafit elektrotlar ve baskısız elektrotlar geliștirilmiștir. Hazırlanan polipirol filmlerine aşırı yükseltgeme işlemi uygulanmıştır. TC’lerin elektrokimyasal davranışları çeşitli yüzdelerdeki asetonitril-su karışımlarında ve farklı pH'larda hazırlanan BR tamponları ortamlarında incelenmiștir.

Hazırlanan modifiye grafit elektrotlar kullanılarak TC'lere karşı seçiciliklerinin kıyaslanabilmesi için TC standartlarının analizi yapılmıștır. Așırı yükseltgenen her iki tür elektrotla yapılan çalışmalardan hangi tür elektrodun tetrasiklin grubu bileşiklere karşı daha duyarlı ve seçici davrandığı tespit edilmiştir. Tetrasiklinlerin moleküler baskılandığı polipirol modifiye grafit elektrot olan MIP ve baskısız elektrot olan NIP elektrodun verdikleri akım cevapları karşılaştırıldığında MIP elektrodun tetrasiklinlere karşı daha duyarlı olduğu ve yüksek seçicilik gösterdiği belirlenmiştir [10].

TC grubu antibiyotikler için bu yöntemle elektrot hazırlama çalışmalarına literatürde rastlanmamıştır. Elektrot hazırlama aşamasının çok kısa olması, modifiye grafit elektrodun tek kullanımlık olması ve pek çok modifiye elektrodun üretilmesine izin vermesi gibi avantajları olan bu yöntem, diğer pek çok analitik yönteme üstünlük sağlamaktadır. Elektrokimyasal olarak TC, CTC ve OTC baskılı polipirol filmlerinin sensör olarak kullanımı gerçekleștirilmiștir. TC'lerin herhangi bir ön ișleme gerek duyulmadan ve düșük maliyetli elektrokimyasal tayinlerinin yapılabilirliği gösterilmiştir.

\section{Teşekkür}

$\mathrm{Bu}$ çalıșma 1821-D-09 numaralı Süleyman Demirel Üniversitesi BAP Lisansüstü Tez projesi kapsamında desteklenmiştir.

\section{Etik Beyanı/Declaration of Ethical Code}

Bu çalışmada, "Yükseköğretim Kurumları Bilimsel Araştırma ve Yayın Etiği Yönergesi" kapsamında uyulması gerekli tüm kurallara uyulduğunu, bahsi geçen yönergenin "Bilimsel Araştırma ve Yayın Etiğine Aykırı Eylemler" başlığı altında belirtilen eylemlerden hiçbirinin gerçekleştirilmediğini taahhüt ederiz.

\section{Kaynakça}

[1] Dökmeci, İ. 2007. Sağlık Yüksek Okulları için Farmakoloji. Medikal Yayıncılık, 9573, İstanbul, 301s. 
[2] Sapadin, A. N., Fleischmajer, R. 2006. Tetracyclines: Nonantibiotic properties and their clinical implications. Journal of the American Academy of Dermatology, 54(2), 258-265.

[3] Özalp Dural, E. A. 2002. Farmakoloji. Genişletilmiș 3. baskı. Nobel Tıp Kitabevleri. Nobel Matbaacılık, 603, İstanbul, 798s.

[4] Şenyuva, H., Gilbert, J. 2010. Hayvansal gida maddelerinde veteriner ilaç kalıntılarının taranması. Food Life International Ltd., Edip Sincer, Sincer Diş Ticaret. https://docplayer.biz.tr/3173220-Hayvansalgida-maddelerinde-veteriner-ilac kalintilarinintaranmasi.html (Erişim tarihi: 25.12.2020)

[5] Perçin Özkorucuklu, S., Şahin, Y., Alsancak, G. 2008. Voltammetric behavior of sulfamethoxazole on eşectropolymerizedmolecularly imprinted overoxidized polypyrrole. Sensors, 8, 8463-8478.

[6] Gürler, B., Perçin Özkorucuklu, S., Kır, E. 2013. Voltammetric behavior and determination of doxycycline in pharmaceuticals at molecularly imprinted and non-imprinted overoxidized polypyrrole electrodes. Journal of Pharmaceutical and Biomedical Analysis, 84, 263-268.

[7] Perçin Özkorucuklu, S., Özcan, L., Şahin, Y., Alsancak, G. 2011. Electroanalytical determination of some sulfonamides on overoxidized polypyrrole electrodes. Australian Journal of Chemistry, 64, 965-972.

[8] Özcan, L., Şahin, Y. 2007. Determination of paracetamol based on electropolymerizedmolecularly imprinted polypyrrole modified pencil graphite electrode. Sensors and Actuators B, 127, 362-369.

[9] Özcan, L., Şahin, M., Şahin, Y. 2008. Electrochemical preparation of a molecularly imprinted polypyrrole-modified pencil graphite electrode for determination of askorbic acid. Sensors, 8, 5792-5805.

[10] Gürler, B. 2011. Bazı tetrasiklinlerin elektrokimyasal davranışlarının belirlenmesi ve voltametrik tayinleri için moleküler baskılanmış polimer modifiye elektrotların hazırlanması. Süleyman Demirel Üniversitesi, Fen Bilimleri Enstitüsü, Doktora Tezi, 116s, Isparta.

[11] Cai, W., Gupta, R. B. 2004. Molecularly-imprinted polymers selective for tetracycline binding. Seperation and Purification Technology, 35, 215221.
[12] Kayaalp, S. O. 2005. Tıbbi Farmakoloji. Hacettepe-Taş Yayını, Feryal Matbaacılık, 27, Ankara, 704s.

[13] Perçin, S. 2008. Bazı sülfonamitlerin elektrokimyasal ve kromatografik davranışlarının incelenmesi. Süleyman Demirel Üniversitesi, Fen Bilimleri Enstitüsü, Doktora Tezi, 170s, Isparta.

[14] Wang, J. 2000. Analytical Electrochemistry. Wiley-VCH, 28272, USA, 209p.

[15] Vega, D., Agüi, L., González-Cortés, A., YáñézSedeño, P., Pingarrón, J. M. 2007. Volatmmetry and amperometric detection of tetracyclines at multi-wall carbon nanotube modified electrodes. Analytical and Bioanalytical Chemistry, 389, 951958.

[16] Zhao, F., Zhang, X., Gan, Y. 2004. Determination of tetracyclines in ovine milk by high-performance liquid chromatography with a coulometric electrode array system. Journal of Chromatography A, 1055, 109-114.

[17] Zhou, J., Gerhardt, G.C., Baranski, A., Cassidy, R. 1999. Capillary electrophoresis of some tetracycline antibiotics coupled with reductive fast cyclic voltammetric detection. Journal of Chromatography A, 839, 193-201.

[18] O'Connor, S., Aga, D.S., 2007. Analysis of tetracycline antibiotics in soil: Advances in extraction, clean-up, and quantification. Trends in Analytical Chemistry, 26, No:6.

[19] Pellegrini, G. E., Carpico, G., Coni, E. 2004. Electrochemical sensor for the detection and presumptive identification of quinolone and tetracycline residues in milk. Analytica Chimica Acta, 520, 13-18.

[20] Majidi, M. R., Jouyban, A., Asadpour-Zeynali, K. 2006. Voltammetric behavior and determination of isoniazid in pharmaceuticals by using overoxidized polypyrrole glassy carbon modified electrode. Journal of Electroanalytical Chemistry, 589, 32-37.

[21] Kazemifard A. G., Moore D. E. 1997. Evaluation of amperometric detection for the liquidchromatografic determination of tetracycline antibiotics and their common contaminants in pharmaceutical formulations. Journal of Pharmaceutical and Biomedical Analysis, 16, 689-696. 